\title{
ANÁLISE DA FRAGILIDADE AMBIENTAL POTENCIAL DA BACIA HIDROGRÁFICA DO CÓRREGO RIBEIRÃO DOIS CÓRREGOS, SELVÍRIA (MS), UTILIZANDO TÉCNICAS DE GEOPROCESSAMENTO
}

\section{Andressa Gouveia Ponso'}

Flávia Joise Izippato²

\section{Vitor Matheus Bacani ${ }^{3}$}

Resumo: O objetivo deste trabalho foi o de analisar a fragilidade ambiental potencial da Bacia Hidrográfica do Córrego Ribeirão Dois Córregos, localizado no município de Selvíria (MS). A proposta do trabalho foi a de elaborar o mapeamento de fragilidade ambiental potencial aos processos erosivos, usando a proposta metodológica de Ross (1994) e Crepani et al. (2001) e adaptando-as. Os resultados indicaram que os maiores índices de precipitação, se concentram no alto e médio curso, associado aos solos Latossolo Vermelho e aos Argilossos. Com relação à fragilidade potencial ambiental o mapa gerado indicou que os locais onde o ambiente está mais frágil aos processos erosivos, são os locais de nascente do alto curso, margens (alto e médio curso) e a foz, fragilidade (forte e muito forte). Tais constatações apresentam forte relação com as características do meio físico-natural, sobretudo com os aspectos geomorfológicos. A proposta metodológica adotada atingiu satisfatoriamente $\mathrm{o}$ objetivo de mapear a fragilidade potencial do ambiente.

Palavras-chave: Bacia Hidrográfica. Análise da Fragilidade Ambiental.

\footnotetext{
${ }^{1}$ Universidade Federal de Mato Grosso do Sul (UFMS) - Campus de Três Lagoas. andressagponso@gmail.com

2 Universidade Federal de Mato Grosso do Sul (UFMS) - Campus de Três Lagoas. flaviajoise@gmail.com

3 Professor Adjunto da Universidade Federal de Mato Grosso do Sul (UFMS) - Campus de Aquidauana. vitor.bacani@ufms.br
} 


\section{INTRODUÇÃO}

Nos tempos atuais, é cada vez mais comum ver áreas naturais sendo substituídas por áreas urbanas e/ou agropecuárias, modificando e interferindo, de forma contundente, os processos de equilíbrio/desequilíbrio da dinâmica da natureza. Este fato é facilmente identificado pela degradação e pelo comprometimento das funções ecológicas dos ambientes, onde há a uma série de impactos na biodiversidade e nos recursos naturais.

Assim, se um ou mais componentes da natureza foi modificado, respectivamente, a configuração espacial também será alterada e uma nova estrutura da paisagem será estruturada. Muitas vezes essa nova estrutura da paisagem está ligada à fragilidade ambiental potencial, ou seja, está vulnerável em sofrer qualquer tipo de dano relacionado com fatores de desequilíbrio tanto de ordem natural (dinâmica do ambiente), quanto antropogênica, por exemplo, o mau uso do solo e intervenções nos regimes fluviais (TAMANINI apud OLIVEIRA et. al., 2012).

De acordo com Ross (1994) "a fragilidade dos ambientes naturais face às intervenções humanas é maior ou menor em função de suas características genéticas". Nesse sentido, a avaliação da fragilidade dos ambientes naturais tem como objetivo o planejamento territorial ambiental, baseada no conceito de Unidades Ecodinâmicas recomendado por Tricart (1977).

Dentro dessa concepção o ambiente é analisado a partir da Teoria dos Sistemas, que parte do pressuposto de que na natureza as trocas de energia e matéria acontecem através de relações de equilíbrio dinâmico. Entretanto, esse equilíbrio é alterado, com certa freqüência, pelas ações antrópicas.

Assim, Tricart (1977) definiu que quando os ambientes estão estáveis é porque eles encontram-se em equilíbrio dinâmico, e quando estão instáveis é porque apresentaram um desequilíbrio (ROSS, 1994).

Sendo assim, Bacani (2010) diz que a aplicação das geotecnologias apresenta-se como uma ferramenta de ordem geográfica destinada a mapeamentos das transformações do uso e cobertura vegetal e da fragilidade ambiental potencial, principalmente em estudos de bacias hidrográficas, servindo como um instrumento de planejamento e gestão do território. 
Desse modo, o objetivo do presente trabalho foi o de analisar a fragilidade ambiental potencial da Bacia Hidrográfica do Córrego Ribeirão Dois Córregos, localizado no município de Selvíria (MS) (Figura 1).

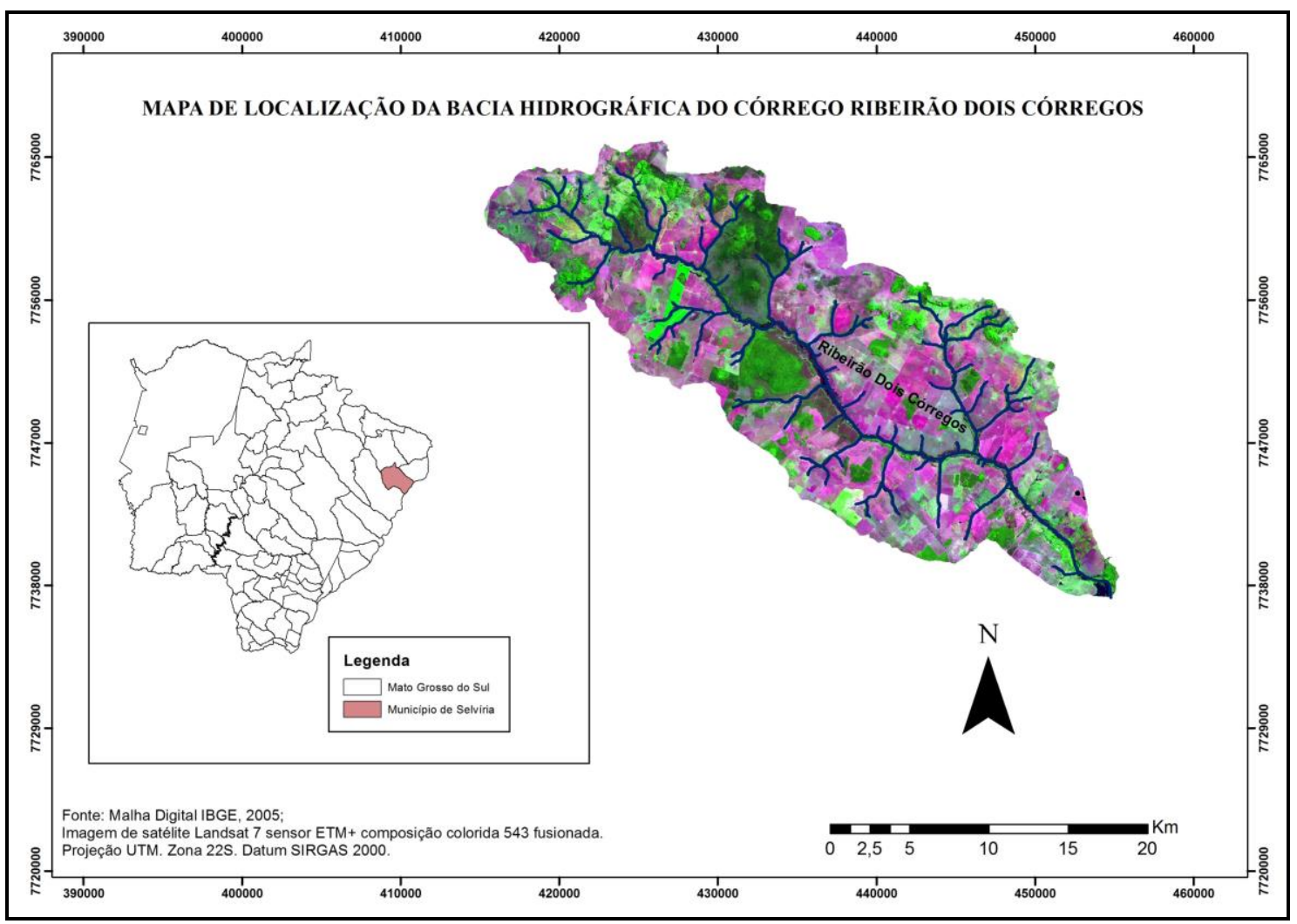

Figura 1: Localização da área de estudo.

\section{PROCEDIMETOS OPERACIONAIS E METODOLÓGICOS}

- Materiais Utilizados - Constitui-se no levantamento de material bibliográfico, cartográfico e iconográfico.

Carta Topográfica de Selvíria Folha: SF-22-V-B escala 1: 250.000.

Imagem do satélite Landsat 7 sensor ETM+ composição colorida 543, fusionada com a banda pancromática, com $15 \mathrm{~m}$ de resolução espacial.

Imagem de radar Shuttle Radar Topographic Mission (SRTM/Topodata) $30 \mathrm{~m}$ de resolução espacial. 
Dados de Pedologia e Áreas Prioritárias para a Conservação da Biodiversidade disponível no Sistema Interativo de Suporte ao Licenciamento Ambiental (SISLA) na escala 1:250.000 disponível em: http://www.sisla.imasul.ms.gov.br/sisla.

Dados de precipitação (média anual mensal) de 6 estações meteorológicas: Porto Galeano, Três Lagoas; Selvíria; Garcia; Inocência e Aparecida do Taboado da Agência Nacional das Águas (ANA), disponível em: http://www.cpao.embrapa.br/clima/.

Software de Sistema de Informações Geográficos: ArcGis $10{ }^{\circledR}$ (licenciado pela Universidade Federal de Mato Grosso do Sul-Aquidauana).

Global Mapper 13 (licenciado pela Universidade Federal de Mato Grosso do SulAquidauana).

Todos os dados da área foram organizados em Banco de Dados Geográficos (SIG), para tratamento e integração das informações e seguem propostas metodológicas como é apresentado:

\section{Procedimentos e Propostas Metodológicas}

A proposta do trabalho de elaborar o mapeamento de fragilidade ambiental potencial aos processos erosivos, foi uma adaptação da proposta metodológica de Ross (1994) e Crepani et al. (2001). Com relação as duas proposta, Ross (1994) apresenta classes de fragilidade, de 1 para fragilidade muito baixa (maior resistência a processos erosivos) a 5 fragilidade muito forte (o contrário) e Crepani et al. (2001) fragilidade: 1 para muito baixa, 2. média e 3 muito alta.

Os mapeamentos temáticos desenvolvidos foram dos dados de pedologia, precipitação e clinográfico sendo adicionada, de acordo com a adaptação metodológica proposta, as informações das áreas prioritárias, definida como a conservação e o uso sustentável e repartição dos benefícios à biodiversidade. Todos os mapas gerados foram inseridos no SIG ArcGis $10 \Theta$ para integração das informações e o mapeamento da fragilidade ambiental potencial. 
Com relação aos procedimentos operacionais dos mapas temáticos de pedologia e áreas prioritárias estes foram desenvolvidos a partir de download das informações de Mato Grosso do Sul, no Sistema Interativo de Suporte ao Licenciamento Ambiental (SISLA, 2008). Sendo os dados de pedologia resultado do macrozoneamento de 1984/1985 e as áreas prioritárias das unidades de conservação - GUC/IMASUL, Instituto de Meio Ambiente de Mato Grosso do Sul. Estes foram importados, como vetor convertido para raster, e o recorte da área foi executado (raster $\rightarrow$ raster processing $\rightarrow$ clip).

O mapa de precipitação foi desenvolvido pelo método de interpolação geoestatístico denominado Inverso do Quadrado da Distância (IQD) (geostatistical analyst tools $\rightarrow$ interpolation $\rightarrow I D W$ ), que é um interpolador determinístico univariado de médias ponderadas. "A interpolação por IQD supõe explicitamente que as feições mais próximas são mais semelhantes do que as mais separadas" (BACANI, 2010, pág. 106).

A imagem do radar SRTM (Topodata/INPE), Modelagem Digital do Terreno, resolução espacial original de 90 metros, refinados por Valeriano (2008) pelo método de Krigagem para 30 metros, foi utilizada para elaborar o mapa clinográfico, em surface $\rightarrow$ slope. A determinação dos intervalos de classes foi adaptada da proposta de Ross (1994), e apresenta os seguintes intervalos: 0 a 3\%; 3 a $6 \% ; 6$ a 12\%; 12 a $30 \%$.

Após a confecção de todos os mapas acima exposto, realizou-se uma operação de álgebra de campo (álgebra de mapas) combinada pelo método da sobreposição ponderada (overlay $\rightarrow$ weighted overlay) e gerou-se o mapa de Fragilidade Ambiental Potencial, sintetizando os diferentes níveis de sensibilidade do ambiente frente a possíveis intervenções antrópicas do Córrego Ribeirão Dois Córregos. As classes de fragilidade mapeadas apresentaram os seguintes: fraca, média, forte e muito forte.

\section{MEIO FÍ́sICO}

\section{Pedologia}

Pedologicamente os solos mapeados foram Latossolo Vermelho Escuro, Argilossolo Amarelo e o Argilosso Vermelho (Figura 2). De acordo com os dados apresentados pela Embrapa Solos (2009), os solos do tipo Latossolo são constituídos por material mineral, 
apresentando horizonte $\mathrm{B}$ latossólico imediatamente abaixo de qualquer tipo de horizonte O Latossolo Vermelho, localizado no alto, médio e baixo curso, constitui-se principalmente pela baixa relação entre teor de ferro e cor; podem ser eutróficos, distróficos e álicos.

Já os Argilossolos, verificado em porções concentradas da área de estudo, são constituídos por material mineral, com argila de atividade baixa ou com argila de atividade alta conjugada com saturação por bases baixa ou caráter alítico na maior parte do horizonte B. Com relação aos Argilossolos Amarelo, foz do Córrego Ribeirão Dois Córregos, é constituído por material mineral, distrófico típico e ocupa paisagens de relevo mais movimentado (EMBRAPA, 2009).

Nas áreas de nascente do rio principal e sudeste, a concentração é do Argilosso Vermelho, que de acordo com a Embrapa (2009) apresenta em sua constituição material mineral, pode ser álico, distrófico, e geralmente com argila de atividade baixa.

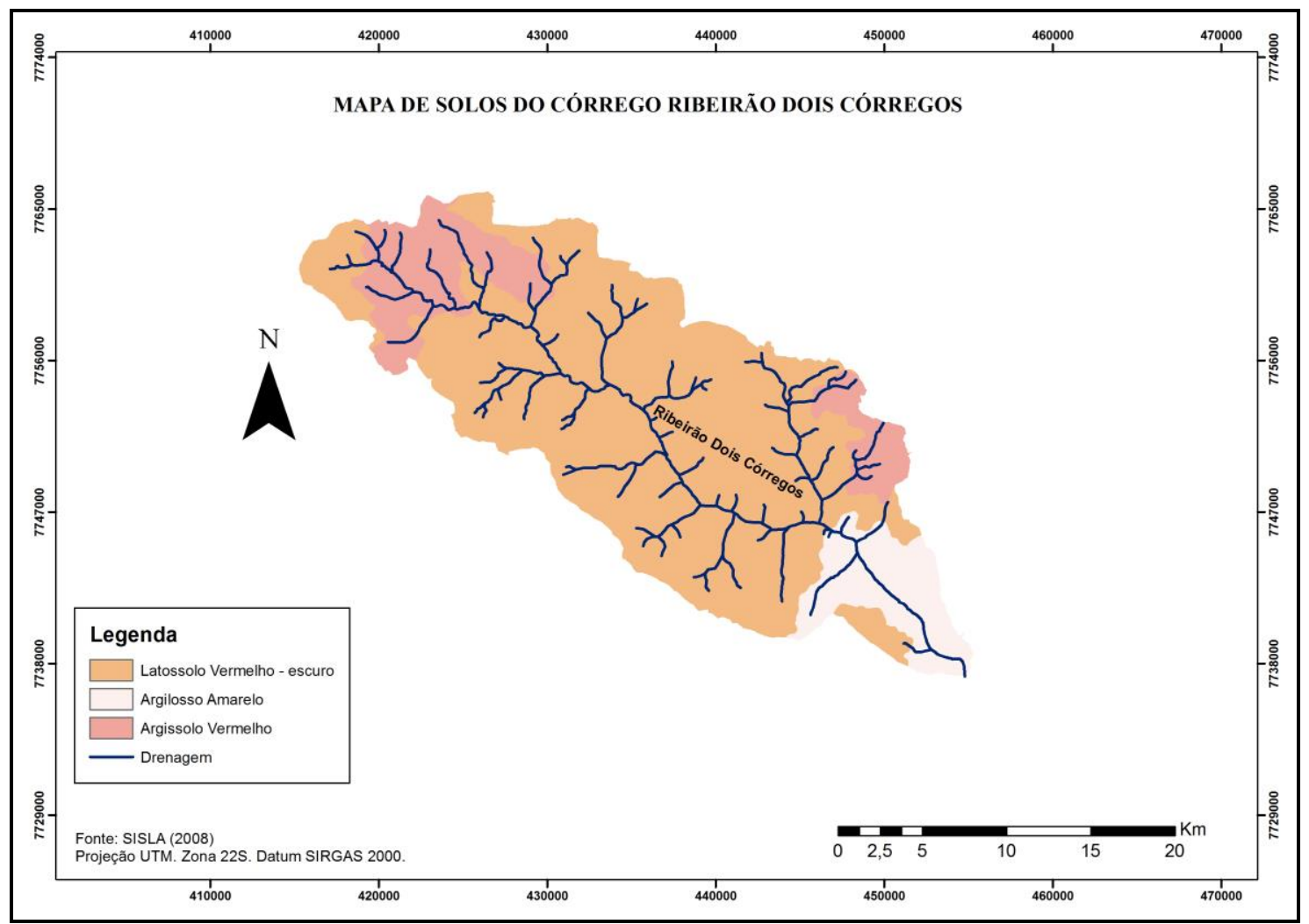

Figura 2: Solos do Córrego Ribeirão Dois Córregos.

Precipitação 
Segundo Zavatini (1992), do ponto de vista climático, a área estudada, encontra-se numa região de domínio de massas de ar equatoriais e tropicais, possuindo clima tropical alternadamente seco, no inverno, e chuvoso, no verão, com altos índices pluviométricos; e pertence à unidade climática "Planalto Arenítico-Basáltico dos Vales do Rio Verde e Baixo Sucuriu".

Com isso constatou-se que os dados que determinaram os índices de precipitação, média total anual mensal, indicam que o Córrego Ribeirão Dois Córregos, recebe os maiores índices de precipitação no alto e médio curso (Figura 3). A nascente apresenta valores médios anuais $1342,6 \mathrm{~mm}$ e o médio curso os índices são de $1271,7 \mathrm{~mm}$. Com relação a tais índices concentrados no alto e médio curso, é viável destacar que o Córrego Ribeirão Dois Córregos esta sendo abastecido de forma mais intensa em suas nascentes do alto e médio curso, propiciando o maior abastecimento e fluxo de drenagem. No baixo curso (foz) os menores índices de precipitação foram verificados, 1190,8mm.

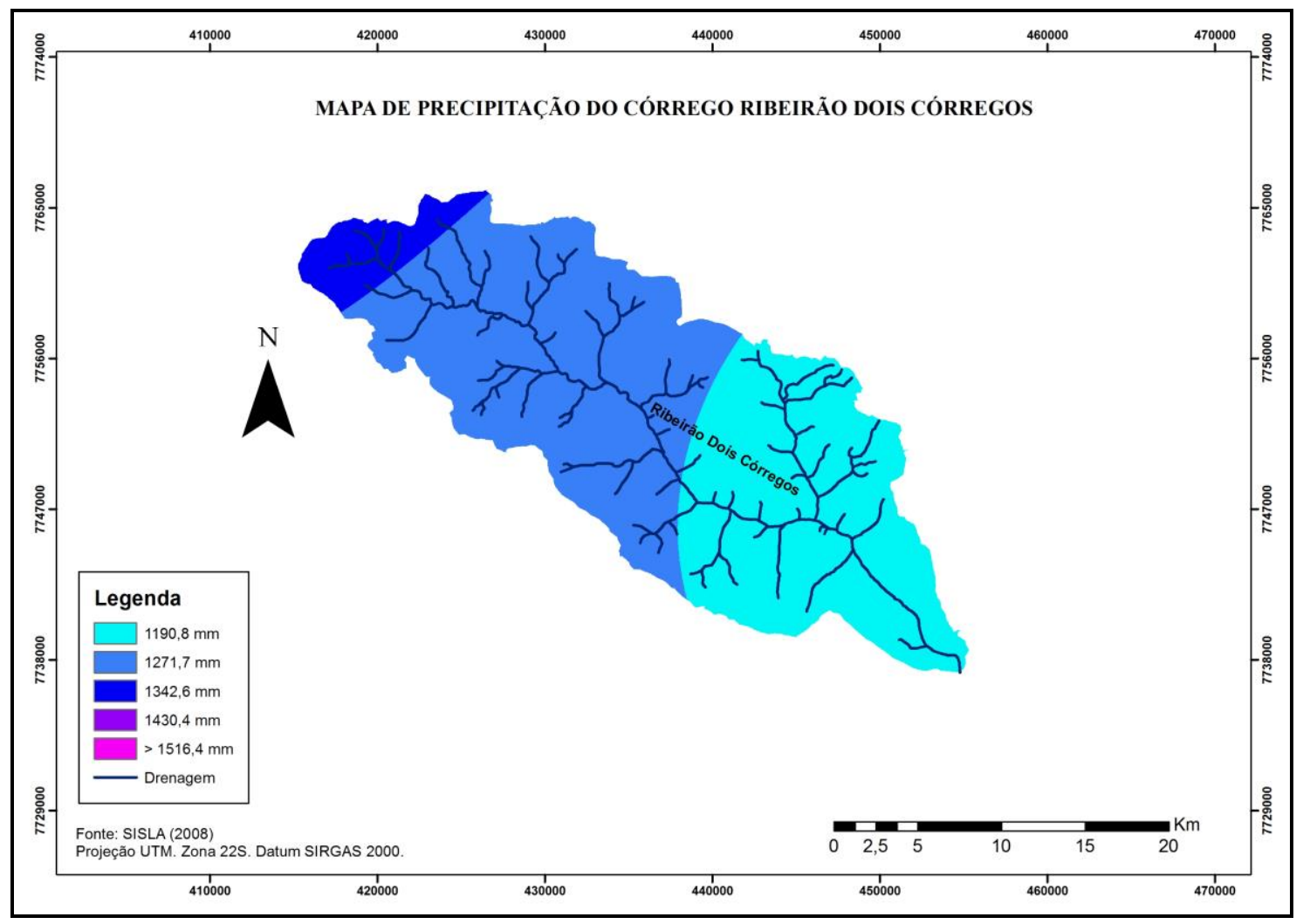

Figura 3: Precipitação do Córrego Ribeirão Dois Córregos. 
As áreas prioritárias indicam os locais onde a conservação, proteção e o Uso devem ser sustentáveis, contudo vale destacar que trata-se de uma ferramenta nova para análise do ambiente, mais devera ser utilizada cada vez mais (MMA, 2007).

Os dados dos locais de riscos á diversidade biológica, são os indicados no mapa como de extremamente alta prioridade (Figura 4). A classe de muito alta prioridade de conservação é a foz do rio principal, onde os índices de cobertura vegetal devem ser mais concentrados, são áreas de fiscalização ambiental, pois apresentam correspondência com as Áreas de Preservação Permanente (APP's).



Áreas Prioritárias do Córrego Ribeirão Dois Córregos.

\section{Declividade}

Os índices clinográficos indicaram que o Córrego Ribeirão Dois Córregos apresenta como característica, relevo bastante aplainado, com maior representatividade de declive a classe de $0-3 \%$ e à classe de 3 á $6 \%$ (Figura 5). Os relevos aplainados têm como principal 
característica a menor perda de solo por fatores erosivos, porém vale destacar que mesmo em relevos mais aplainados, problemas com relação à perda de solo são verificados.

$\mathrm{Na}$ região nestes locais é comum verificar, quase que constantemente o manejo inadequado, ou até a mesma a falta dele, associado ao intenso uso da área pela pecuária extensiva por tempo prolongado. Áreas em que pode-se observar quase que frequentemente erosões em sulcos e laminar, provocadas pelo intenso pisoteio do gado, e também a compactação do solo.

Com relação à classe que corresponde aos maiores índices de elevação no terreno, os valores com maior representatividade, no mapeamento, é a classe de 6 á $12 \%$, indicando realmente o baixo índice de elevação no Córrego Ribeirão Dois Córregos.

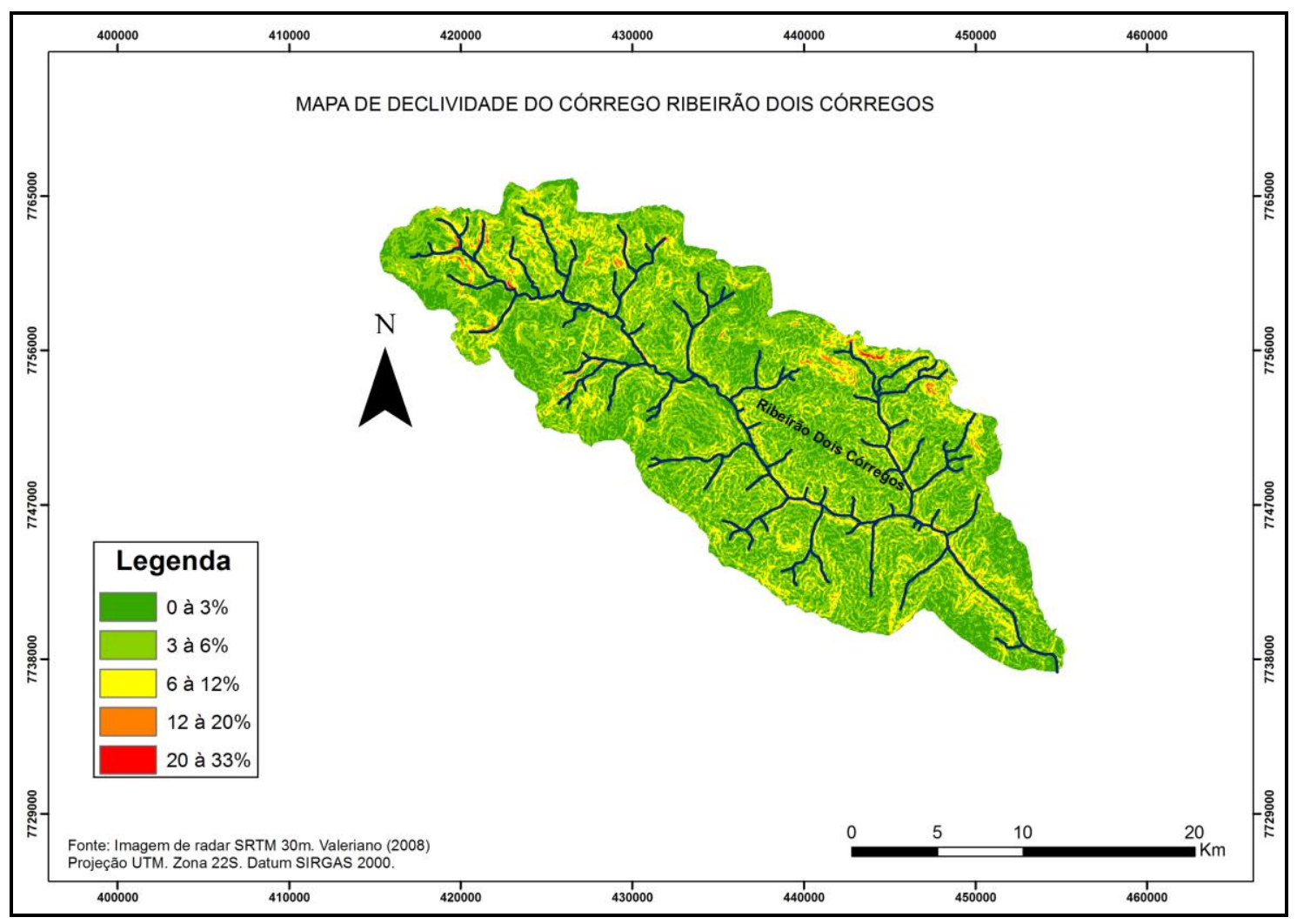

Figura 5: Declividade do Córrego Ribeirão Dois Córregos.

\section{RESULTADOS}


O mapeamento do Córrego Ribeirão Dois Córregos mostra que a fragilidade ambiental potencial muito forte, esta concentrada no alto curso 3.3\% (Figura 6), nascente do rio principal, local onde se verificou um relevo com altas inclinações, os maiores índices de precipitação, associado à concentração do solo Argilossolo Vermelho, que devido à baixa quantidade de argila no horizonte $A$, associado à concentração no horizonte $B$ (b textural), propiciam normalmente solos menos coeso, consequentemente sujeito aos processos erosivos.

Além disso, são áreas que legalmente devem ser protegidas permanentemente (APP’s) impressa no novo Código Florestal Lei № 12.651 de 25 de maio de 2012： Art. 4 (BRASIL, 2012). Como pode ser verificado nos índices na Tabela 1.

\begin{tabular}{|c|c|c|}
\hline Jlasses de Fragilidade & $\begin{array}{ll}\begin{array}{l}\text { Área } \\
\text { km² }^{2}\end{array} & \text { em } \\
\end{array}$ & $\%$ \\
\hline Fraca & 81 & 15.8 \\
\hline Média & 229 & 44.8 \\
\hline Forte & 184 & 36.1 \\
\hline Muito Forte & 17 & 3.3 \\
\hline Total & 511 & 100 \\
\hline
\end{tabular}

A classe com forte Fragilidade Ambiental Potencial são as áreas mais próximas às margens, nascentes e a foz $36.1 \%$. Estes são locais mais vulneráveis a degradação do ambiente e que devem sempre estar protegidos por cobertura vegetal (mata ciliar).

As classes de fraca fragilidade potencial e média fragilidade potencial são locais onde normalmente se verifica maior representatividade de cobertura vegetal, como foi verificado no mapa de áreas prioritárias, nestes as áreas apresentaram o menor risco a perda de solo por erosão. A classe de fraca fragilidade correspondeu a $15.8 \%$ e a média 44.8\% e compreende a maior área do Córrego Ribeirão Dois Córregos. 


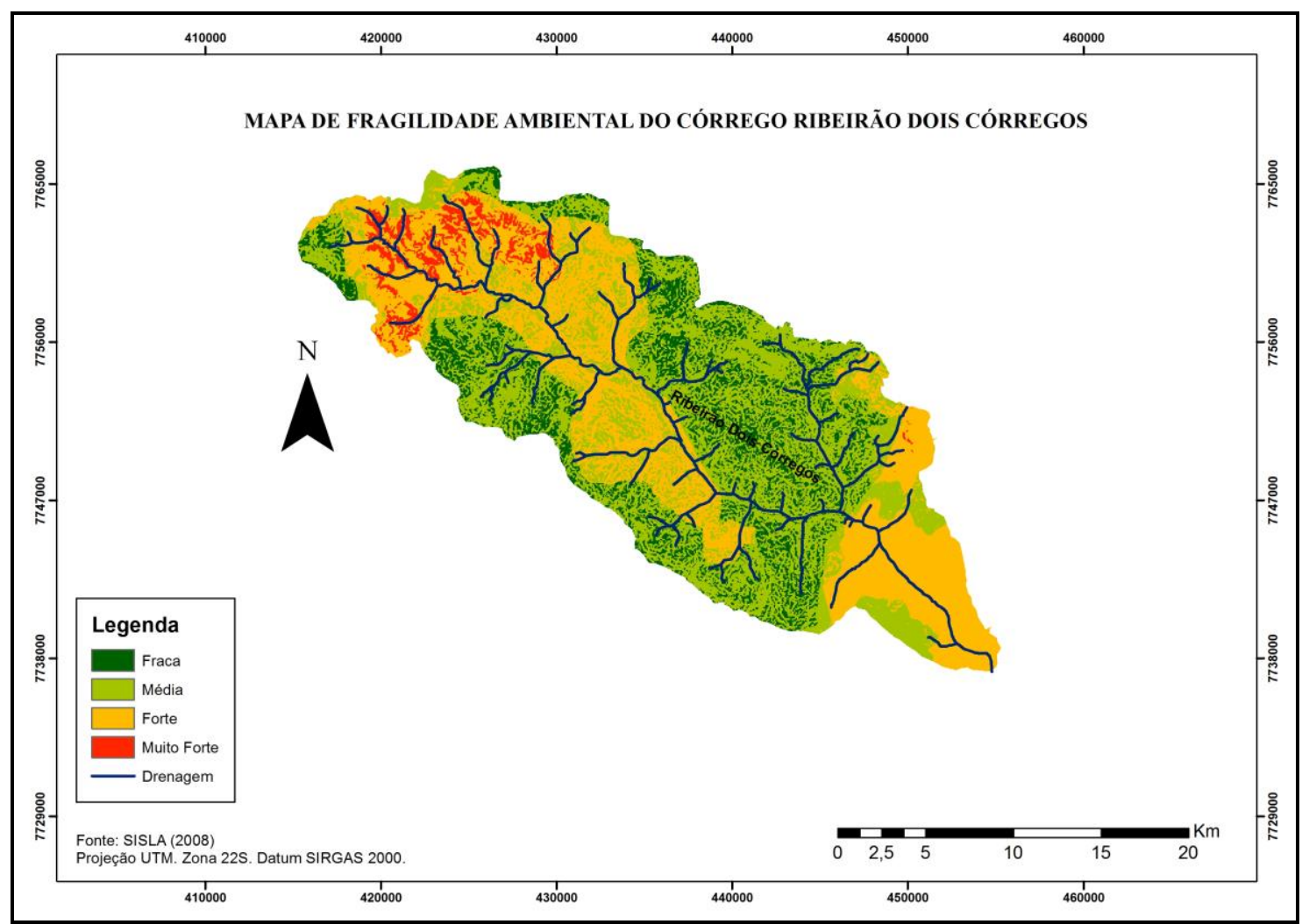

Figura 6: Fragilidade ambiental potencial do Córrego Ribeirão Dois Córregos.

\section{CONCLUSÃO}

Com relação ao trabalho, verificou-se que os maiores índices de precipitação, se concentram no alto e médio curso, associado aos solos Latossolo Vermelho e aos Argilossos. Já com relação à fragilidade potencial ambiental o mapa gerado indicou que os locais onde o ambiente está mais frágil aos processos erosivos, são os locais de nascente do alto curso, margens (alto e médio curso) e a foz, fragilidade (forte e muito forte). Tais constatações apresentam forte relação com as características do meio físico-natural, sobretudo com os aspectos geomorfológicos.

A proposta metodológica adotada atingiu satisfatoriamente o objetivo de mapear a fragilidade potencial do ambiente, no entanto, sugere-se em futuros trabalhos a avaliação da fragilidade emergente, com intuito de analisar as propostas do ambiente frente aos diferentes tipo de uso da terra desenvolvidos em diferentes classes de fragilidade potencial, de modo a subsidiar ações para um planejamento territorial estratégico. 


\section{BIBLIOGRAFIA}

BACANI, V. M. Geotecnologias aplicadas ao ordenamento físico-territorial da bacia do alto rio Coxim, MS. 2010. Tese (Doutorado em Geografia Física). Universidade de São Paulo, São Paulo, 2010 .

BRASIL. Ministério do Meio Ambiente. Secretaria Nacional de Biodiversidade e Florestas. Departamento De Conservação Da Biodiversidade. Áreas Prioritárias Para Conservação, Uso Sustentável e Repartição de Benefícios da Biodiversidade Brasileira. Portaria MMA n.ำ 9, de 23 de janeiro de 2007. Brasília, 2007.

CREPANI, E.; MEDEIROS, J. S.; FILHO, P. H.; FlORENZANO, T. G.; DUARTE, V. BARBOSA, C. C. F. Sensoriamento Remoto e Geoprocessamento Aplicados ao Zoneamento Ecológico Econômico e ao Ordenamento Territorial. São José dos

Campos: SAE/INPE, 2001.

EMPRESA BRASILEIRA DE PESQUISA AGROPECUÁRIA - EMBRAPA. Sistema Brasileiro de Classificação de Solos. Brasília: Serviço de Produção de Informação, 2009.

OLIVEIRA, Rafael G. de; et. al. Análise da fragilidade ambiental potencial da bacia hidrográfica do córrego São João-MS utilizando geoprocessamento. Revista Brasileira de Cartografia, № 64/1, p. 15-24, 2012.98897

ROSS, J. L. S. Análise Empírica da Fragilidade dos Ambientes Naturais e Antropizados. Revista do Departamento de Geografia. São Paulo: FFLCH-USP , n8, 1994.

SANTOS, Rosely F. dos. Vulnerabilidade ambiental: desastre natural ou fenômeno induzidos. Brasília: MMA, 2007.

TRICAR T. J. Ecodinâmica. Rio de Janeiro: IBGE/SUPREN (Recursos Naturais e Meio Ambiente), 1977.

ZAVATINI, J. A. Dinâmica climática no Mato Grosso do Sul. Geografia. Rio Claro: IGCE/UNESP, 1992. v. 17(2), pp. 65-91. 